\title{
Indoleamine 2,3-dioxygenase overexpression causes kynurenine-modification of proteins, fiber cell apoptosis and cataract formation in the mouse lens
}

\author{
Maneesh Mailankot ${ }^{1}$, Magdalena M Staniszewska ${ }^{1}$, Heather Butler ${ }^{2}$, Moonkyung H Caprara ${ }^{2}$, Scott Howell ${ }^{2}$, \\ Benlian Wang ${ }^{2}$, Catherine Doller ${ }^{2}$, Lixing W Reneker ${ }^{3}$ and Ram H Nagaraj, ${ }^{1,2}$
}

Indoleamine 2,3-dioxygenase (IDO) is the first enzyme in the kynurenine pathway. The kynurenines formed in this pathway chemically modify proteins and cause apoptosis in cells. Evidence suggests that kynurenines and their protein modifications are involved in cataract formation, but this has yet to be directly demonstrated. We generated transgenic (Tg) mouse lines that overexpress human IDO in the lens. Homozygous Tg (homTg) lenses had higher IDO immunoreactivity, $\sim 4.5$ times greater IDO mRNA, and $\sim 8$ times higher IDO activity compared to lenses from hemizygous $\mathrm{Tg}$ (hemTg) animals. The kynurenine content was threefold higher in homTg than in hemTg but was not detected in wild-type (Wt) lenses. Kynurenine modifications were $\sim 2.6$ times greater in homTg than in hemTg or Wt. HomTg lenses had vacuoles in the epithelium and cortical fiber cells. Kynurenine modifications coincided with apoptosis in the secondary fiber cells of homTg lenses. Caspase-3 and caspase-9 activities were markedly higher in homTg than in hemTg and $\mathrm{Wt}$. The glutathione content was $\sim 36 \%$ lower in homTg compared to hemTg and Wt lenses. HomTg animals also developed bilateral cataracts within 3 months of birth. Together these data demonstrate that IDO-mediated production of kynurenines results in defects in fiber cell differentiation and their apoptosis and suggest that IDO activity is kept low in the lens to prevent deleterious effects by kynurenines.

Laboratory Investigation (2009) 89, 498-512; doi:10.1038/labinvest.2009.22; published online 23 March 2009

KEYWORDS: crystallin; cataract; kynurenine; indoleamine 2,3-dioxygenase

The kynurenine $(\mathrm{KYN})$ pathway is the primary route of L-tryptophan catabolism and a source of NAD. ${ }^{1}$ In extrahepatic tissues, the KYN pathway is initiated by indoleamine 2,3dioxygenase (IDO). IDO is a heme-containing dioxygenase; it oxidizes L-tryptophan to N-formylkynurenine (NFK). Further catalysis of NFK leads to the formation of NAD. ${ }^{2}$ IDO synthesis is induced by inflammatory stimuli, especially interferon- $\gamma$. Enhanced synthesis of IDO appears to deplete tryptophan and restrict viral and bacterial growth and infection. ${ }^{3}$ IDO has been implicated in the protection of fetal allografts from maternal T-cell-mediated immunity, possibly through KYN-mediated apoptosis of thymocytes. ${ }^{4,5}$ Inhibition of T-cell-mediated immunity by IDO is also involved in engraftment of skin substitutes ${ }^{6}$ and transplantation of other organs. ${ }^{7}$ IDO secreted by tumor cells starves T cells by depleting tryptophan, ${ }^{8}$ and inhibition of IDO promotes tumor regression. ${ }^{9}$ Thus, IDO appears to have important functions in infection, inflammation, and T-cell-mediated immunity.

Although these effects are defensive strategies to cope with infection and inflammation, they may have unintended consequences because KYNs formed during IDO-mediated degradation of tryptophan can chemically modify proteins and have been shown to be cytotoxic. ${ }^{10,11}$ In coronary heart disease, inflammation and immune activation are associated with increased blood levels of KYN, ${ }^{12}$ possibly through interferon- $\gamma$-mediated activation of IDO. In experimental chronic renal failure, activation of IDO leads to increased blood levels of KYNs, ${ }^{13}$ and in uremic patients KYN-modified proteins are present in urine. ${ }^{14}$ Further, renal IDO expression may be deleterious during inflammation because it enhances tubular cell injury. ${ }^{15}$ KYNs and IDO also are implicated in the pathophysiology of neurodegenerative

\footnotetext{
${ }^{1}$ Department of Ophthalmology and Visual Sciences, Case Western Reserve University, Cleveland, OH, USA; ${ }^{2}$ Visual Sciences Research Center, Case Western Reserve University, Cleveland, OH, USA and ${ }^{3}$ Department of Ophthalmology, University of Missouri, Columbia, MO, USA

Correspondence: Professor RH Nagaraj, PhD, Department of Ophthalmology and Visual Sciences, Pathology Building, Room 311, Case Western Reserve University, 2085 Adelbert Road, Cleveland, OH 44106, USA.

E-mail: ram.nagaraj@case.edu
}

Received 3 July 2008; revised 9 December 2008; accepted 12 December 2008 
diseases, including Alzheimer's, Parkinson's, and Huntington's diseases, and KYNs have been shown to be neurotoxic. $^{10,16-19}$ Tryptophan degradation increases in rheumatoid arthritis ${ }^{20}$ and development of collagen-induced arthritis in mice is associated with increased IDO activity and enhanced tryptophan catabolism. ${ }^{21}$ These observations suggest that KYN may contribute to various neurological, renal, and inflammatory pathologies. Chronic inflammation in these diseases may be an underlying factor for IDO overexpression.

Several recent studies, especially those investigating the eye lens, shed light on how KYNs might chemically alter protein structure. In the human lens, IDO activity is present mainly in the anterior epithelium. ${ }^{22}$ Several KYNs, such as KYN, 3-hydroxykynurenine, and 3-hydroxykynurenine glucoside, are present in the lens. ${ }^{23}$ They are thought to protect the retina by absorbing UV light and therefore are commonly referred to as UV filters. However, several recent studies show that KYNs are prone to deamination and oxidation. ${ }^{24}$ The deamination results in formation of $\alpha, \beta$-unsaturated ketones that chemically react and modify lens proteins. Such reactions occur mostly at cysteinyl, histidinyl, and lysyl residues. ${ }^{25}$ The predominant modifications appear to be Michael adducts; however, other more stable and proteincross-linking adducts also are likely, but their structures are not fully understood.

In the normal human lens, KYN modifications increase after 50 years of age, ${ }^{26}$ and in cataractous lenses they decrease due to degradation. ${ }^{27}$ Our studies, using highly specific monoclonal antibodies (mAbs), have provided additional support for the presence of Michael adducts in proteins of the human lens. ${ }^{28,29}$ These observations suggest that KYNmediated modification could contribute to the lens protein modifications during aging and cataractogenesis. They may also reduce the chaperone function of $\alpha$-crystallin, which is necessary for maintaining lens transparency. ${ }^{30}$ Although these observations link KYN formation to aging and cataract formation, whether KYN formation is directly involved in lens protein modification and cataract development has yet to be demonstrated. To address this issue, we have generated transgenic mouse lines that express high levels of IDO in the lens. Using this model, we show that IDO overexpression adversely affects lens development, causes massive apoptosis of fiber cells, and leads to poorly differentiated fiber cells and cataract formation.

\section{MATERIALS AND METHODS Establishment of Transgenic Mouse Lines Expressing hIDO}

The studies conformed to the ARVO Statement on the Use of Animals in Ophthalmic and Vision Research and were approved by the Case Western Reserve University Institutional Animal Care and Use Committee. Two independent transgenic mouse lines were produced by the standard pronuclear microinjection technique. The details of the transgene DNA

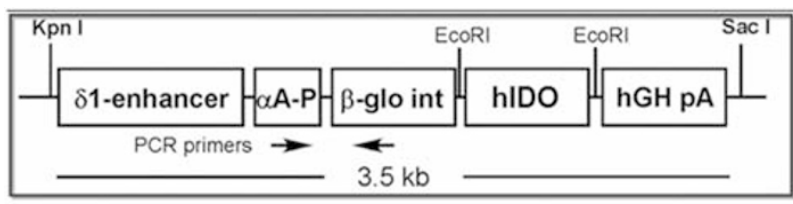

Figure 1 Transgene. Schematic representation of the hIDO transgenic construct. The chick $\delta 1$-crystallin enhancer $(\delta 1)$ was fused to the mouse $\alpha \mathrm{A}$ crystallin promoter $(\alpha \mathrm{A}-\mathrm{P})$ to make the chimeric promoter, $\delta$ en $\alpha \mathrm{A}$. The hIDO cDNA was inserted between the $\beta$-globin intron ( $\beta$-glo int) and human growth hormone polyA signal (hGH pA, $660 \mathrm{bp}$ ).

construct are illustrated in Figure 1. The human IDO (hIDO) gene was inserted between EcoR1 sites of a minigene construct, which contained a chick $\delta 1$-crystallin lens enhancer upstream of the $\alpha \mathrm{A}$-crystallin promoter and a rabbit $\beta$-globin intron. Human growth hormone polyA was inserted downstream from the $\alpha \mathrm{A}$-crystallin promoter. At 2-3 weeks after birth, tail biopsies were obtained, and genomic DNA was screened for the transgene integration using PCR with forward primer $5^{\prime}$-TCTGAGAGCCTCTGCTGCTC-3' and reverse primer $5^{\prime}$-GGTCCATGGTGATACAAGGGAC-3'. Identified founders were crossed with wild-type (Wt) C57BL/ 6 to establish a hemizygous transgenic (hemTg) line. Homozygous transgenic (homTg) mouse lines were established by breeding the hemizygous mice within the same line.

\section{Morphological Changes}

Mice were killed by $\mathrm{CO}_{2}$ asphyxiation. Following dissection, lenses were immediately placed on an electron microscopy grid to assess opacity. Lenses were then examined in bright field using a $\times 4$ objective on an Olympus BX-60 upright microscope (Olympus, Tokyo, Japan). Images were captured in color using a SPOT RT Slider camera (Diagnostic Instruments, Sterling Heights, MI, USA). Lens diameter measurements were carried out using Spot software version 3.5.5.

\section{Hematoxylin and Eosin Staining}

Immediately after dissection, eyes were fixed in 10\% neutralbuffered formalin, embedded in paraffin, cut into $5-\mu \mathrm{m}$ sections, and stained with hematoxylin and eosin using a standard procedure.

\section{Electron Microscopy}

Mouse eyeballs were fixed with triple aldehyde-DMSO fixative for $2 \mathrm{~h}$ at room temperature. The specimens were thoroughly rinsed in $0.1 \mathrm{M}$ phosphate buffer $(\mathrm{pH} 7.4)$, and then fixed for $2 \mathrm{~h}$ in a buffered 1:1 mixture of $2 \%$ osmium tetroxide and 3\% potassium ferricyanide. After rinsing in water, the specimens were soaked overnight in an acidified solution of $0.25 \%$ uranyl acetate. After another rinse in distilled water, they were dehydrated in ascending concentrations of ethanol, passed through propylene oxide, and embedded in an Epon mixture. Sections $(80 \mathrm{~nm})$ were cut with an RMC MT 6000$\mathrm{XL}$ ultramicrotome. The sections were sequentially stained 
with acidified methanolic uranyl acetate and lead tartrate and examined with a JEOL 1200EX transmission electron microscope.

\section{Slit Lamp Imaging}

Animals were anesthetized by 2,2,2-tribromoethanol in 2-methyl-2-butabol (both from Sigma-Aldrich) (i.p. injection at $0.2 \mathrm{ml}$ per $10 \mathrm{~g}$ ). Pupils were dilated with topically applied $0.5 \%$ mydriacyl and examined using a fixed slit lamp with an adapted Nikon D2Xs digital SLR camera. Images were taken using axial light with full illumination. Slit beams were offset by $10^{\circ}$; minimum beam size was used and additional fill light was provided with a fiber optic source.

\section{IDO Activity}

Lenses were homogenized on ice in $200 \mu \mathrm{l}$ PBS and centrifuged $\left(14000 \mathrm{~g}, 4^{\circ} \mathrm{C}, 15 \mathrm{~min}\right)$. Supernatants containing water-soluble proteins were used for the IDO assay. The reaction mixture contained $50 \mathrm{mM}$ sodium phosphate buffer (pH 6.5), $20 \mathrm{mM}$ ascorbic acid sodium salt, $200 \mu \mathrm{g} / \mathrm{ml}$ bovine liver catalase (Sigma-Aldrich), $10 \mu \mathrm{M}$ methylene blue, and $400 \mu \mathrm{M}$ L-tryptophan. The reaction was carried out at $37^{\circ} \mathrm{C}$ for $1 \mathrm{~h}$ and was stopped with $40 \mu \mathrm{l} 30 \%$ (w/v) trichloroacetic acid (TCA). The samples were incubated at $65^{\circ} \mathrm{C}$ for $15 \mathrm{~min}$ to convert NFK to KYN and then centrifuged $\left(14000 \mathrm{~g}, 4^{\circ} \mathrm{C}\right.$, $15 \mathrm{~min}$ ). Controls were prepared in the same way except that the water-soluble protein was incubated with an IDO inhibitor, $20 \mu \mathrm{M}$ 1-methyl-D,L-tryptophan (Sigma-Aldrich). KYN content was estimated by reverse-phase HPLC along with standards ranging from 0.2 to $5.0 \mathrm{nM}$ L-KYN (SigmaAldrich) using a GraceVydac C18 column $(250 \times 4.6 \mathrm{~mm}$, $5.0 \mu \mathrm{m})$ with ammonium acetate $(10 \mathrm{mM})$ as solvent $\mathrm{A}$ and $10 \%$ methanol in ammonium acetate as solvent $\mathrm{B}$. The percentage of solvent $\mathrm{B}$ in the gradient was $0 \%(10 \mathrm{~min})$, $0-100 \%(10 \mathrm{~min})$, and $100-0 \%(15 \mathrm{~min})$. The flow rate was $0.8 \mathrm{ml} / \mathrm{min}$. The eluant was monitored at $360 \mathrm{~nm}$ (Jasco UV970 UV-VIS detector), and the peak areas were determined using PowerChrom software. IDO activity was expressed as nanomoles of KYN formed per milligram protein per minute. Protein concentration was determined using the Bio-Rad reagent.

\section{Immunostaining of IDO}

After rehydration in xylene and ethanol series, paraffin-embedded eye sections were treated with citrate buffer ( $\mathrm{pH}$ 6.0) for $20 \mathrm{~min}$ at $70^{\circ} \mathrm{C}$, cooled, and then incubated in $3.0 \%$ hydrogen peroxide to block endogenous peroxidase. The sections were incubated with streptavidin $\mathrm{D}$ and biotin blocking solution for $15 \mathrm{~min}$ each at room temperature and then in mouse-on-mouse (M.O.M; Vector Laboratories, CA, USA) Ig blocking solution for $1 \mathrm{~h}$ at room temperature. After washing in PBS, sections were incubated in M.O.M. diluent, followed by incubation in mouse anti-IDO $\mathrm{mAb}$ (Chemicon International, CA, USA) diluted to $24 \mu \mathrm{g} / \mathrm{ml}$ in PBS, overnight at $4^{\circ} \mathrm{C}$. After thorough washing in PBS, the slides were incubated with M.O.M. biotinylated anti-mouse IgG reagent and rinsed thoroughly in PBS. The slides were then incubated in $\mathrm{ABC}$ Vectastain Elite Peroxidase (Vector Laboratories) and rinsed in PBS. Sections were stained by incubating in 3,3'diaminobenzidine substrate, rinsing thoroughly in deionized water, and counterstained with hematoxylin. The negative control was processed similarly, but without the primary antibody. The slides were viewed with an Olympus BX-60 upright microscope (Olympus). Images were captured in color using a SPOT RT Slider camera (Diagnostic Instruments) connected to a Macintosh computer using Spot software version 3.5.5.

\section{Quantification of hIDO mRNA}

RNA was extracted from lenses using TRIZOL reagent, and RNA quality was verified by agarose gel electrophoresis. cDNA was generated using the Super Script First Strand Synthesis System for RT-PCR (Invitrogen). Total RNA, $2.5 \mu \mathrm{g}$, was denatured, then reverse-transcribed using random primers in a reaction mixture containing RT buffer, $10 \mathrm{mM}$ dNTP, RNase inhibitor, reverse transcriptase, and DTT at $42^{\circ} \mathrm{C}$ for $1.5 \mathrm{~h}$ in a Bio-Rad iCycler. Amplification was verified by electrophoresis.

The hIDO cDNA was first amplified with gene-specific primers: forward 5'-CACTTTGCTAAAGGCGCTGTTGGA-3' and reverse $5^{\prime}$-GGTTGCCTTTCCAGCCAGACAAAT- $3^{\prime}$ using the Invitrogen PCR Reagent System. The PCR product was $140 \mathrm{bp}$ and the amplification specificity was verified by electrophoresis. The cDNA concentration was determined and standards ranging from $1 \times 10^{9}$ to $1 \times 10^{0}$ cDNA molecules were prepared. Real-time PCR was performed on duplicate samples and the standards using SYBR Green PCR Master Mix (Applied Biosystems). The PCR protocol comprised an initial denaturation step at $95^{\circ} \mathrm{C}$ for $10 \mathrm{~min}$ followed by 40 cycles of denaturation $\left(95^{\circ} \mathrm{C}, 15 \mathrm{~s}\right.$ each) and annealing/extension $\left(60^{\circ} \mathrm{C}, 1 \mathrm{~min}\right)$. In preliminary experiments, the PCR products were visualized by agarose gel electrophoresis to verify that a single product was amplified. Real-time PCR data were analyzed with an ABI PRISM 7700 detector using ABI PRISM 7700 dissociation curve software (Applied Biosystems).

\section{Kynurenine Content}

Lenses were weighed and homogenized in $100 \mu \mathrm{l}$ ethanol. The homogenate was stored at $-20^{\circ} \mathrm{C}$ for $1 \mathrm{~h}$ and then centrifuged $\left(14000 \mathrm{~g}, 10^{\circ} \mathrm{C}, 15 \mathrm{~min}\right)$. The supernatant was removed, kept at $-20^{\circ} \mathrm{C}$ whereas the pellet was reextracted with $100 \mu \mathrm{l}, 80 \%$ ethanol. The homogenate was kept at $-20^{\circ} \mathrm{C}$ for $1 \mathrm{~h}$, centrifuged as before, and the supernatants were combined and dried in a SpeedVac concentrator. Samples and standards $(0.2-5.0 \mathrm{nmol}$ of $\mathrm{KYN})$ were analyzed by reversephase HPLC as described above. Sodium acetate $(20 \mathrm{mM}) /$ acetic acid buffer ( $\mathrm{pH} 4.5)$ used as solvent $\mathrm{A}$ and $20 \%$ methanol as solvent $\mathrm{B}$. The percentage of solvent $\mathrm{B}$ in the gradient was $0 \%$ (30 min), $0-50 \%$ ( $2 \mathrm{~min}$ ), $50-100 \%$ ( $8 \mathrm{~min}$ ), 
and $100-0 \%$ ( $6 \mathrm{~min})$. The flow rate was $0.6 \mathrm{ml} / \mathrm{min}$. KYN was expressed as $\mathrm{nmol} / \mathrm{mg}$ lens.

\section{ELISA for Kynurenine-Mediated Lens Protein Modification}

Microplate wells were coated with water-soluble lens proteins in $0.05 \mathrm{M}$ carbonate buffer $(\mathrm{pH} 9.7)$ at a concentration of $1 \mu \mathrm{g}$ per $50 \mu \mathrm{l}$, incubated for $1 \mathrm{~h}$ at $4^{\circ} \mathrm{C}$, and then washed three times with PBST. The wells then were blocked with 5\% nonfat dry milk in PBST and washed three times with PBST. The primary antibody, mouse anti-KYN mAb ${ }^{29}$ (1:1000 diluted in PBS), was added, the plates were incubated for $1 \mathrm{~h}$ at $37^{\circ} \mathrm{C}$, washed with PBST, and then incubated with HRPconjugated goat anti-mouse IgG secondary antibody (Promega; 1:15 000 in PBST). Substrate was added $\left(3,3^{\prime}, 5,5^{\prime}\right.$ tetramethylbenzidine (Sigma-Aldrich) with $\mathrm{H}_{2} \mathrm{O}_{2}$ ), the reaction stopped, and absorbance was measured at $450 \mathrm{~nm}$. Primary and secondary antibody specificity was verified by preincubating the primary antibody with KYN-modified RNase A and incubating coated wells with secondary antibody only.

\section{Immunostaining for Kynurenine Modification}

After rehydration, high-temperature antigen retrieval, and incubation in $3.0 \% \mathrm{H}_{2} \mathrm{O}_{2}$, paraffin-embedded sections were blocked with goat serum. The sections were rinsed briefly in PBS and incubated with anti-KYN mAb (1:500 diluted in PBS) or anti-KYN mAb incubated with KYN-modified RNase A. Sections were then incubated with goat anti-mouse IgG Texas Red (1:400 diluted in PBS; Molecular Probes), rinsed, incubated with DAPI/Vectashield, and then permanently mounted. The negative control was processed similarly but without the primary antibody. Images of lenses were acquired on a Leica DMI 6000 B inverted microscope using a $\times 20$ objective and a Retiga EXI camera (QImaging, Vancouver, BC, USA). To obtain 'stitched' images, Metamorph software (Molecular Devices Corp., Downingtown, PA, USA) was used.

\section{Incubation of Lens Homogenate with L-Tryptophan}

Water-soluble lens protein was incubated with or without $1 \mathrm{mM}$ L-tryptophan for $12 \mathrm{~h}$ at $37^{\circ} \mathrm{C}$, after which the samples were mixed with an equal volume of $20 \%$ TCA and centrifuged at $14000 \mathrm{~g}, 10^{\circ} \mathrm{C}, 15 \mathrm{~min}$. The supernatant was assayed for KYN by reverse-phase HPLC as described above. $\mathrm{KYN}$ concentrations were expressed as $\mathrm{pmol} / \mathrm{mg}$ protein.

\section{Organ Culture with L-Tryptophan}

Each lens was carefully dissected by a posterior approach and placed in the well of a 12-well culture plate containing $2 \mathrm{ml}$ M199 medium (pH 7.4, $300 \pm 5$ mOsm; Sigma-Aldrich) and incubated for $6 \mathrm{~h}$ in a $\mathrm{CO}_{2}$ incubator. Only transparent lenses were selected for further assay. M199 medium containing $1 \mathrm{mM}$ L-tryptophan (stock made in $2 \mathrm{~N} \mathrm{NaOH}$ ) was prepared $(\mathrm{pH} 7.4$ and $300 \pm 5 \mathrm{mOsm})$. The medium was changed every $24 \mathrm{~h}$ for 3 days, after which KYN was assayed by reverse-phase HPLC as described above and was expressed as $\mathrm{nmol} / \mathrm{mg}$ lens.

\section{Measurement of Glutathione}

Glutathione (GSH) was determined according to the method of Cui and Lou. ${ }^{31}$ Lens homogenate was prepared as described above for the incubation with L-tryptophan, and $10 \mu \mathrm{l}$ was mixed with $10 \mu \mathrm{l}$ 5,5'-dithiobis(2-nitrobenzoic acid) $(2.0 \mathrm{mg}$ per $2.5 \mathrm{ml}$ methanol). The volume was adjusted to $200 \mu$ l with $1.0 \mathrm{M}$ Tris- $\mathrm{HCl}$ buffer (pH 8.2), containing $0.02 \mathrm{M}$ EDTA. Absorbance of the reaction product was measured at $412 \mathrm{~nm}$.

\section{Apoptosis}

After rehydration and antigen retrieval by microwave irradiation in $0.1 \mathrm{M}$ citrate buffer ( $\mathrm{pH}$ 6.0), paraffin-embedded sections were stained for apoptosis in situ using a kit (In situ Cell Death Detection Kit; Roche) as per the manufacturer's instructions. The sections were counterstained with DAPI. For the negative control, sections were incubated without terminal transferase.

\section{Measurement of Caspase-3 and Caspase-9 Activity}

Freshly dissected whole lenses were homogenized in $50 \mathrm{mM}$ Tris-buffered saline. An equal volume of fluorogenic substrate solution $(2 \times$ reaction buffer: $10 \mathrm{mM}$ DTT, and $50 \mu \mathrm{M}$ Ac-DEVD-AFC (for caspase-3) or Ac-LEHD-AFC (for caspase-9)) was added to each lysate. Lysates were incubated for $2 \mathrm{~h}$ at $37^{\circ} \mathrm{C}$ in the dark. Samples were read in a spectrofluorometer (FluoroMax-4; HORIBA Jobin Yvon, USA) at excitation/emission wavelengths of $400 / 505 \mathrm{~nm}$. Recombinant human caspases (Calbiochem) were used as positive controls.

\section{Identification of KYN-Modified Proteins}

Lens homogenate from $\mathrm{Wt}$ or homTg lenses corresponding to $200 \mu \mathrm{g}$ protein in PBS was incubated with $2 \mu \mathrm{g}$ mouse anti$\mathrm{KYN}$ mAb or nonimmune IgG for $1 \mathrm{~h}$ at room temperature followed by addition of protein G-sepharose. The mixture was again incubated on a shaker for $1 \mathrm{~h}$ at room temperature. After centrifugation the pellet was washed five times with PBS. To do SDS-PAGE, the pellet was boiled with SDS sample buffer for $5 \mathrm{~min}$ at $95^{\circ} \mathrm{C}$, centrifuged and the supernatant was run on $15 \%$ Tris- $\mathrm{HCl}$ buffer. The gel were stained with Bio-Safe staining solution (Bio-Rad) and destained in water. A major protein band (indicated by an arrow in Figure 10c) was cut out from the gel, minced, and subjected to in-gel digestion with trypsin and the peptides were analyzed on an LTQ linear ion trap mass spectrometer (Thermo Fisher Scientific) coupled with an Ettan MDLC system (GE Healthcare). The spectra were acquired by data-dependent methods: one full scan $(\mathrm{m} / \mathrm{z}$ of $300-2000)$ followed by MS/MS on the five most abundant precursor ions at the $30 \%$ normalized collision energy. The dynamic exclusion was set as follows: 
repeat count, 1; repeat duration, $45 \mathrm{~s}$; and exclusion duration $180 \mathrm{~s}$. The obtained data were submitted to Mascot by searching Swiss-Prot (sprot 50.3) mouse database, which includes 228670 sequences, 83849098 residues.

\section{Statistics}

The results were analyzed using one-way analysis of variance, followed by the Fisher's protected least significant difference test (using Statview 5.0 software, SAS Institute Inc.). The level of significance was set at less than 0.05 .

\section{RESULTS}

\section{Transgenic Mouse Lines}

One hemizygous-independent and two homozygous-independent lines were established. HomTg lines were characterized by smaller eyes (Figure 2a). All transgenic lines showed normal reproductive patterns and longevity. Both nontransgenic and transgenic animals received the same diet and developed normally. In addition, to control for possible effects of the promoter on morphological and developmental features in the hIDO overexpression animals, we examined eyes and lenses from C57BL/6 mice that overexpress glyoxalase-I. In this mouse, the chicken $\delta 1$-crystallin enhancer and $\alpha \mathrm{A}$-crystallin promoter construct were used to drive overexpression of glyoxalase-I in the lens (Gangadhariah et al., unpublished observation) but lens development and morphology were normal. We used $\sim 3$-month-old mice for the entire study, as at this age homTg animals had bilateral mature cataracts (see below).

\section{Morphological Changes}

Lenses from the homTg lines failed to attain normal weight and diameter. Compared to $\mathrm{Wt}$, in homTg lenses the weight was reduced by $91 \%$ and the diameter was reduced by $64 \%$ (Figure $2 \mathrm{~b}$ and $2 \mathrm{c}$ ). HomTg lens shape and histology also differed (Figure 3). The anterior and posterior segments lacked typical opposite-end curvature and clearly failed to overlap and form normal suture branches between and within successive growth shells (Figure $3 \mathrm{a}$ ). The lens epithelium in homTg lenses had vacuoles (Figure $3 \mathrm{~b}$ ). The equatorial segments were also vacuolated in these lenses (Figure 3c). In homTg, a large number of nucleated cells were present throughout lens, indicating defects in denucleation of fiber cells (Figure 3d). In contrast, lenses from hemTg, Wt, and glyoxalase-I-overexpression mice contained no vacuoles or nucleated fiber cells.

To investigate ultrastructural morphological differences in epithelial and fiber cells, we prepared homTg and Wt lenses for thin-section electron microscopy. In the $\mathrm{Wt}$, the fiber cell architecture was regular (Figure 4a). Characteristic gap junctions were frequent between fiber cells. In contrast, in homTg lenses, the fiber cells were disorganized and swollen with many large vacuolar structures (Figure 4b). Gap junctions were scarce. The epithelial cells in Wt lenses formed a monolayer, and both epithelial and fiber cells showed tight
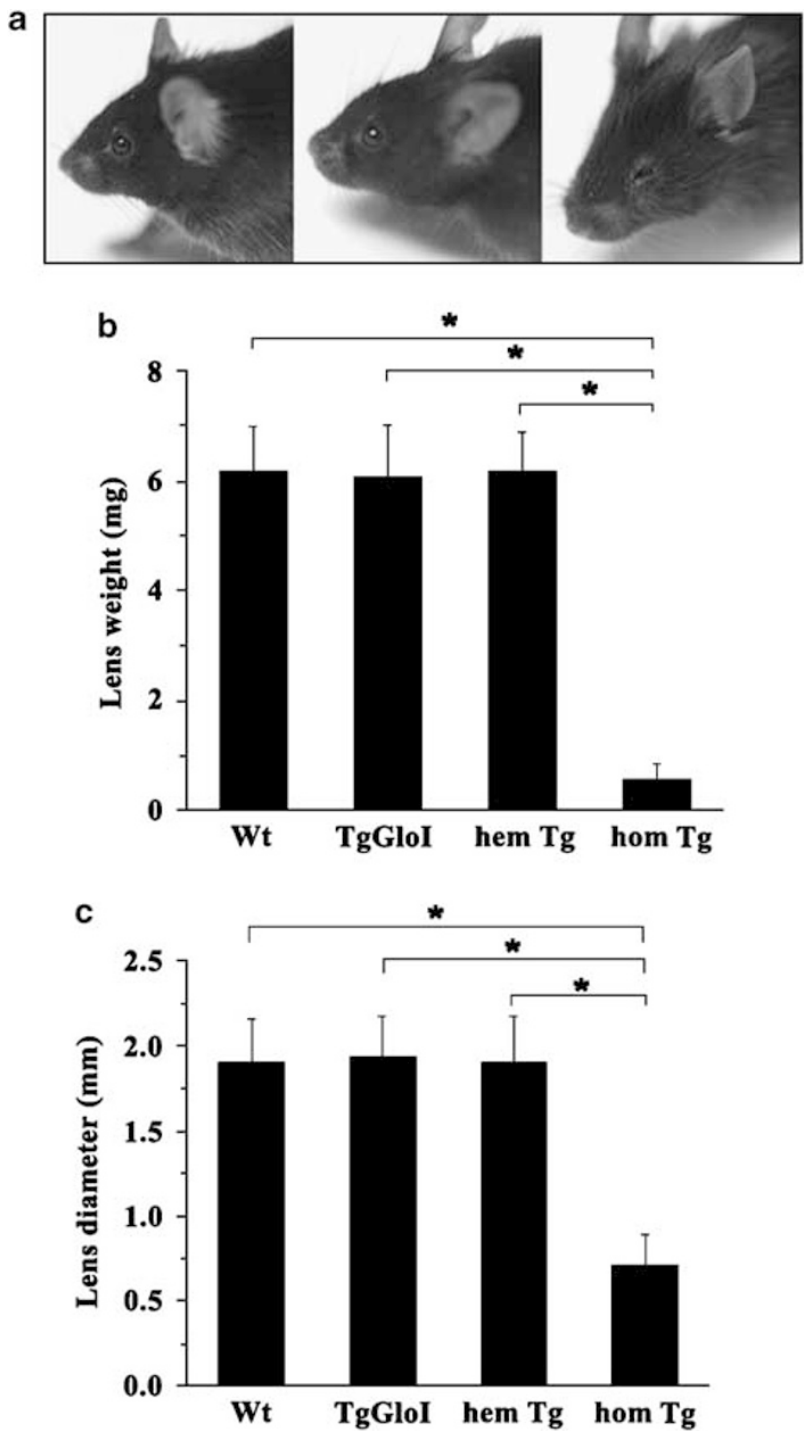

Figure 2 Lens diameter in the transgenic mouse. (a) Homozygous transgenic (homTg) mice (right) exhibited considerably smaller lenses. The eye size was normal in age-matched hemizygous transgenic (hemTg) (middle) and wild-type (Wt) mice (left). (b) Lens weight was significantly lower in homTg mice compared to Wt, glyoxalase-l-transgenic (TgGlol), and hemTg mice. (c) Lens diameter in homTg mice was significantly shorter than Wt, TgGlol, and hemTg mice. Results are mean \pm s.d., $n=5$ mice (10 lenses). ${ }^{\star} P<0.0001$.

connections in lenses (Figure 4c). In contrast in homTg lenses, the epithelial cells irregularly arranged, interdigitated with each other, and were loosely opposed to the fiber cells (Figure 4d).

Lenses from homTg lines had a strikingly dense nuclear cataract (Figure 5a) and opacity (Figure 5b); the cataract developed in both homozygous lines after about 3 months of age. The hemTg lens had no evidence of cataract formation and was similar to the $\mathrm{Wt}$ and glyoxalase-I-overexpression mouse lenses at this age. 
a

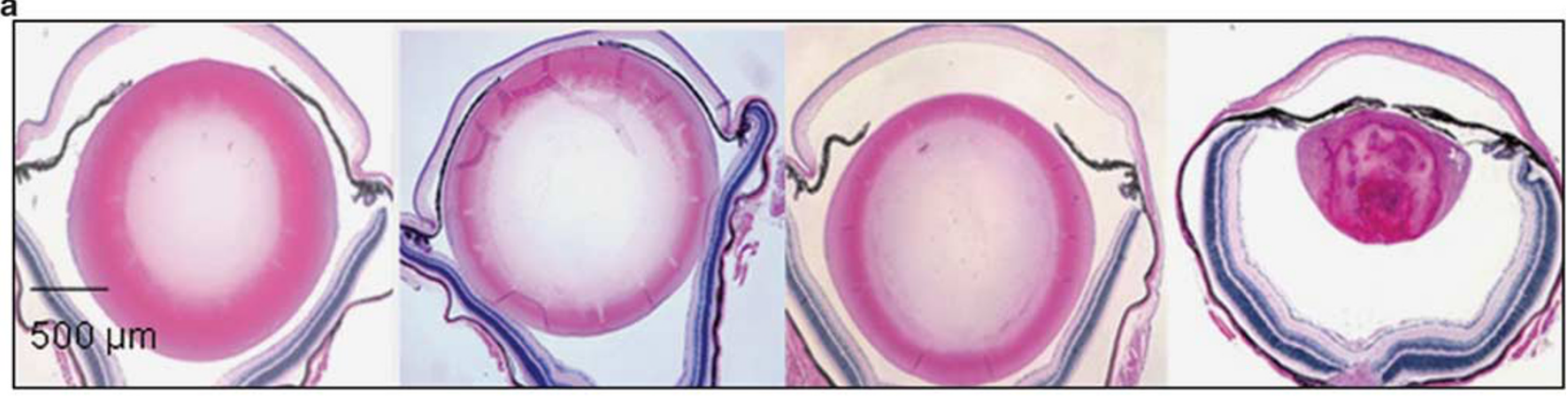

Wt

TgGloI

hemTg

homTg

b

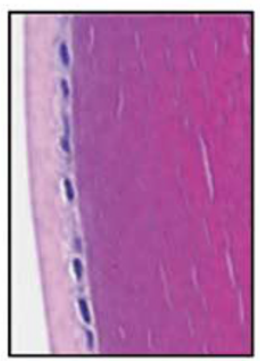

C

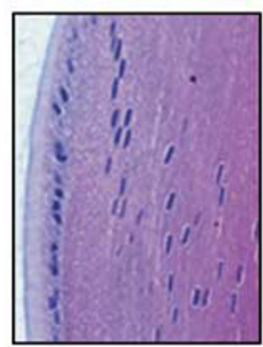

d

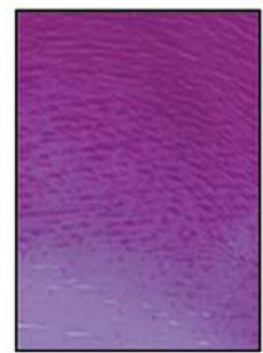

Wt
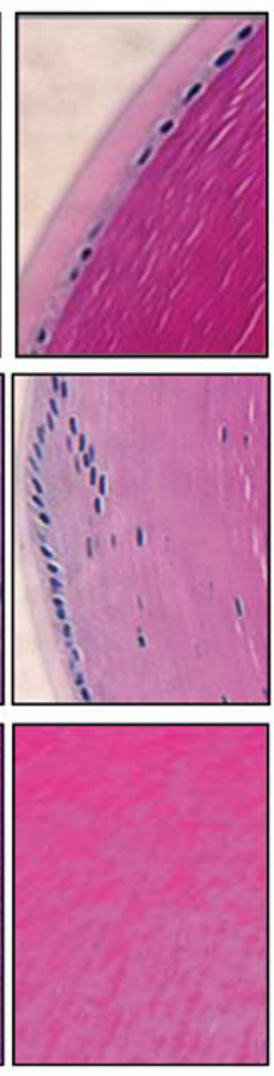

TgGloI
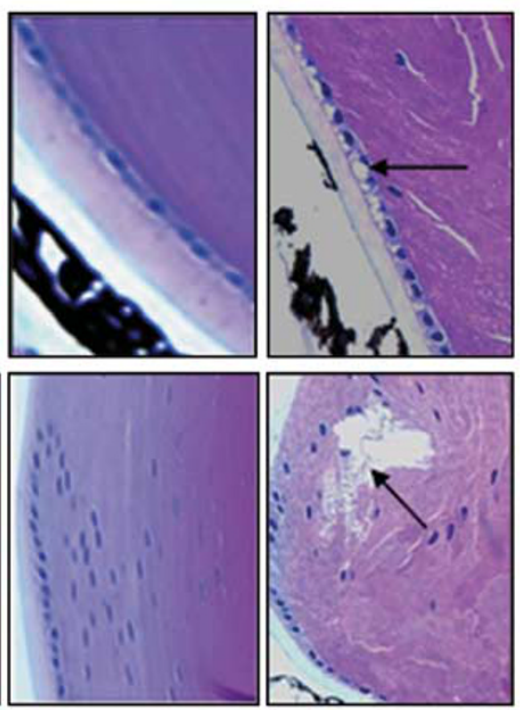

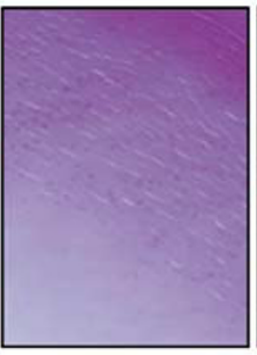

hemTg

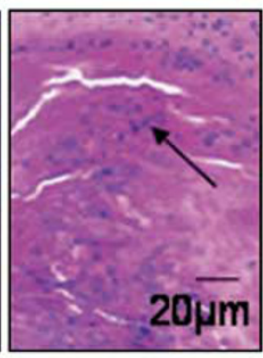

homTg

Figure 3 Morphological changes in the lens. Hematoxylin and eosin staining revealed differences in homTg lenses compared to Wt and other transgenic lines. (a) In the whole eye, the lens shape and size differed markedly in homTg. (b) The epithelial cells of homTg lenses had vacuoles (arrow). (c) At the lens equator, the homTg lens had vacuoles (arrow). (d) In the lens nucleus, the homTg lens had nucleated fiber cells (arrow). In contrast, all three features were normal in hemTg, TgGlo l, and Wt lenses (magnification: $\mathbf{a}, \times 4$; $\mathbf{b}, \mathbf{c}$, and $\mathbf{d}, \times 10$ ).

\section{IDO Overexpression}

IDO activity in the lens was quantified by estimating the amount of KYN formed upon incubation of water-soluble lens proteins with $1 \mathrm{mM}$ L-tryptophan. Reverse-phase HPLC revealed a peak at $12-14$ min that corresponded to KYN (Figure 6a). Both homTg and hemTg lenses showed IDO activity whereas the Wt showed negligible activity (Figure 6b). Enzyme activity increased approximately eightfold in homTg compared to hemTg lenses. Heat treat- ment $\left(65^{\circ} \mathrm{C}, 15 \mathrm{~min}\right)$ abolished enzyme activity, and incubation with the IDO inhibitor, 1-methyl tryptophan resulted in a $40 \%$ reduction in the enzyme activity in homTg lens proteins confirming that the measured activity was from IDO.

IDO localization in the lens was determined by immunohistochemistry (Figure 6c). In homTg lens, prominent $\mathrm{DAB}$ staining was observed throughout the lens. In hemTg lens, staining occurred only in the anterior epithelium and to 
Wt
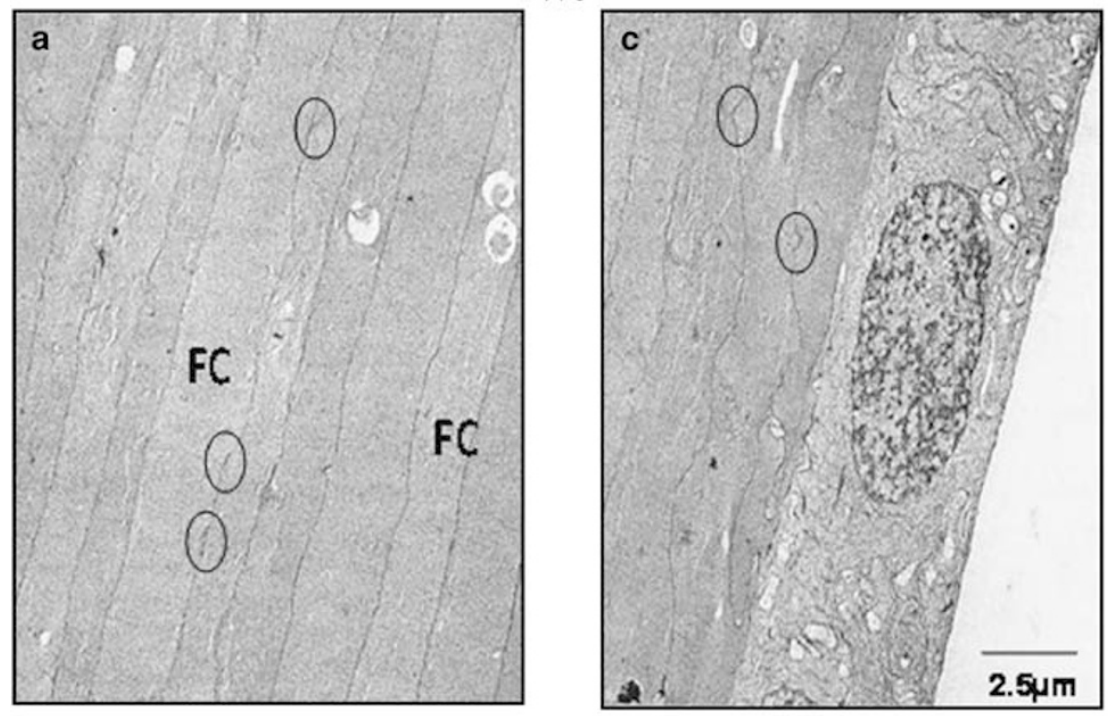

homTg
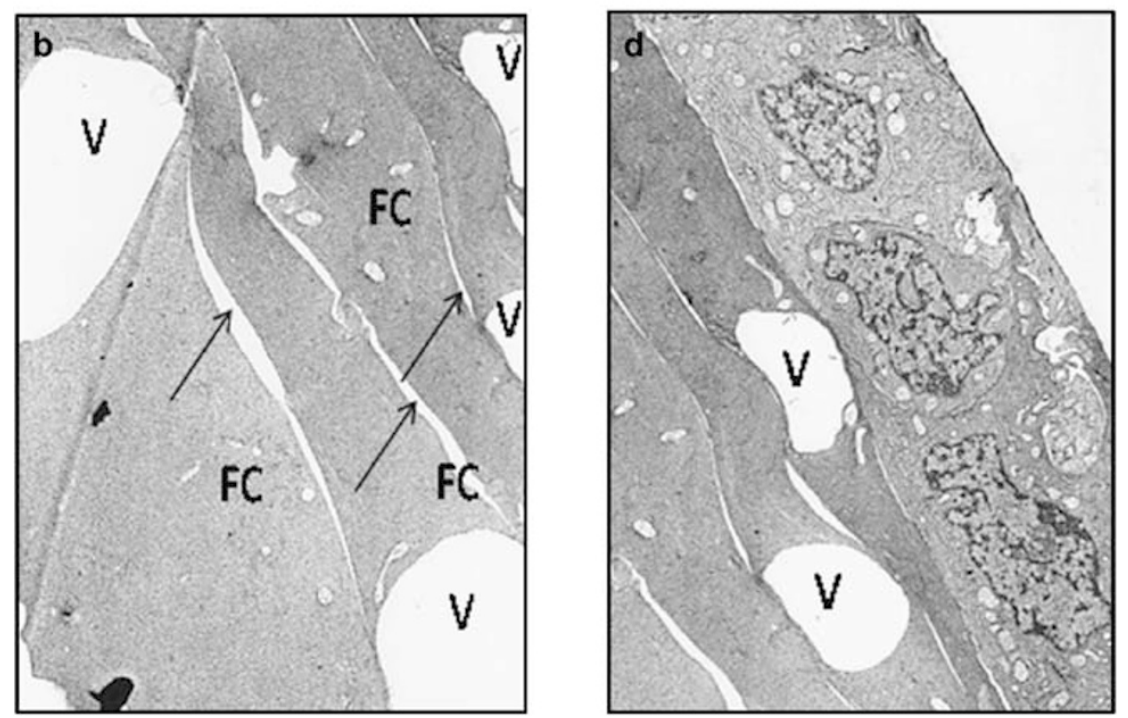

Figure 4 Morphological changes in the lens revealed by electron microscopy. The Wt lens had normal fiber cell architecture (a) and flat epithelial cells (c). The fiber cells in homTg (b) were disorganized and had large vacuole-like structures. The epithelial cells in homTg (d) were irregularly arranged. Arrowhead indicates space between the epithelial and fiber cells and between fiber cells. Circles indicate gap junctions. Magnification, $\times 10000$. FC, fiber cell; V, vacuole.

some extent in the bow region and outer posterior regions. The negative control where the primary antibody was omitted did not show immunoreaction. The Wt lens did not show appreciable DAB staining. Western blotting using an $\mathrm{mAb}$ for hIDO showed a protein band corresponding to the molecular weight of IDO $(45 \mathrm{kDa})$.

The hIDO mRNA level was assessed with real-time PCR. The mRNA level was 4.5-fold higher in homTg than in hemTg lenses. Wt lenses showed no hIDO mRNA (Figure 6d). These data suggest that both the IDO transcript and protein are elevated in homTg and hemTg lenses and resulted in higher enzyme activity.

\section{Kynurenine Content and Protein Modification}

Lenses from transgenic animals showed KYN, whereas it was not detected in Wt lenses (Figure 7a). KYN levels were approximately threefold higher in lenses from homTg compared to those from hemTg. To determine if KYN formation occurred in younger than 3-month-old lenses, we determined KYN content in 1-month-old Wt and homTg lenses. At this age, homTg lenses were transparent, but much smaller than Wt lenses of same age. The KYN levels at this age were already elevated (Supplementary Figure S1a).

KYN-modified proteins were measured by a direct ELISA. The mAb used in this assay was developed by us and 


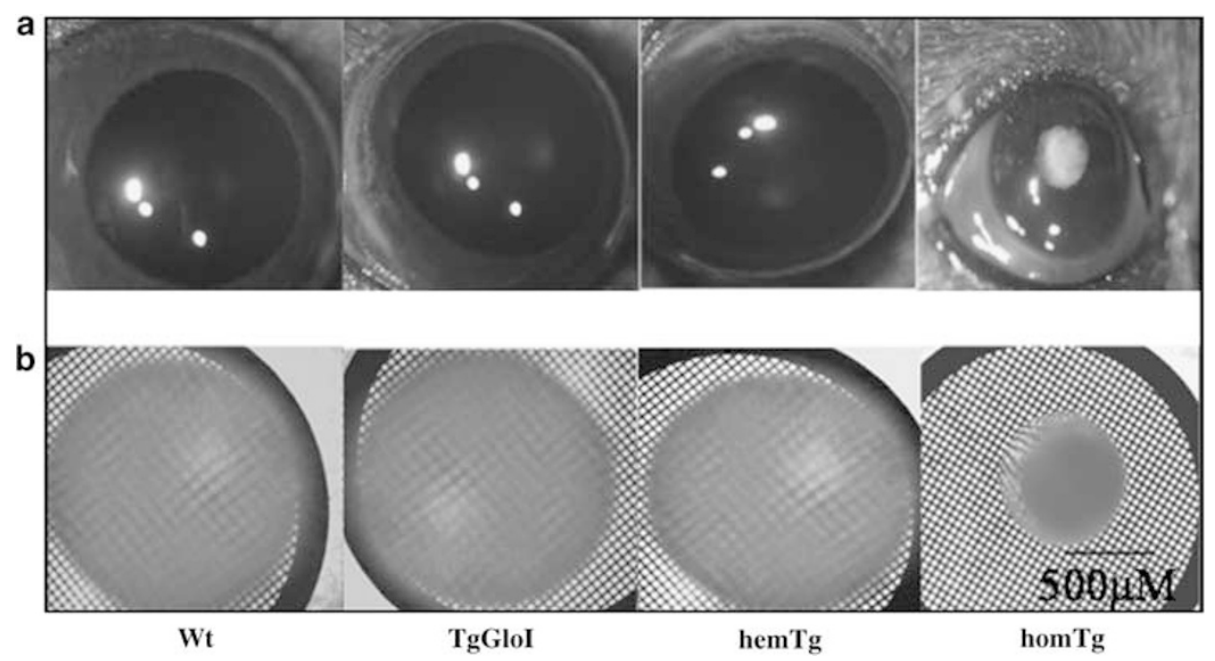

Figure 5 Lens opacity in transgenic mice. (a) Slit lamp images revealed that lenses from homTg mice were cataractous by 3 months of age. (b) Threemonth-old homTg lenses had marked opacity. Lenses from age-matched hemTg, TgGlo I, and Wt mice were normal.

it recognizes mainly the Michael adduct formed from the reaction of histidine with deaminated $\mathrm{KYN}^{25}$ The homTg lenses exhibited $\sim 2.7$ times greater $\mathrm{KYN}$ modifications compared to hemTg lenses. The lenses from Wt showed little modifications (Figure $7 \mathrm{~b}$ ). No immunoreactivity was present when the primary antibody was preincubated with KYN-modified RNase A (data not shown). These data suggest that overexpression of hIDO resulted in greater $\mathrm{KYN}$ and $\mathrm{KYN}$-modified proteins in the transgenic animal lenses.

To localize lens protein modifications produced by KYN, we performed immunohistochemistry on paraffin-embedded sections. Immunoreactivity was present throughout the homTg lens, but predominated in the central nuclear region (Figure 7c). The hemTg (C2) lenses showed much weaker immunoreactivity compared to the homTg (C3). Interestingly, immunoreactivity in homTg lenses coincided with the nucleated fiber cells. The immunoreactivity was markedly reduced when the antibody was preincubated with KYNmodified RNase A (C6). Together these results demonstrate that in transgenic lenses, enhanced IDO activity leads to higher KYN content and KYN-modified proteins. These results also suggest that KYN modifications may be responsible for nucleated undifferentiated fiber cells.

To determine if KYN modification preceded cataract development, we determined KYN modification by immunohistochemistry in 1-month-old homTg and Wt lenses. Unlike 3-month-old lenses (Figure 7, C3), 1-month-old lenses showed KYN modified proteins in the outer cortical region, more densely at the bow regions (Supplementary Figure S1b). These observations together with results in Supplementary Figure S1a suggest that KYN formation and KYN modification of proteins occur before development of mature cataracts in homTg animals.

\section{Incubation of Lens Homogenate and Lens Organ Culture with L-Tryptophan}

Incubation of water-soluble lens proteins from transgenic mice with L-tryptophan resulted in KYN formation (Figure 8a). KYN formation increased approximately sevenfold in proteins from homTg lens compared with hemTg lenses. The Wt lens proteins did not produce KYN. These experiments also revealed that $\sim 12 \%$ of added L-tryptophan was converted to KYN within $1 \mathrm{~h}$ in homTg lens protein extract, whereas only $\sim 1.5 \%$ was converted in hemTg lens proteins.

To determine whether KYN formation occurs in intact lenses, we performed organ culture experiments, in which we incubated whole lenses with $1 \mathrm{mM}$ L-tryptophan. Similar to results for isolated proteins, KYN increased by 5 -fold in homTg lenses and 3.2-fold in hemTg lenses (Figure 8b). The formation of KYN from lens proteins and whole lenses of transgenic animals also suggests that IDO overexpression causes higher production of KYN in the lens.

\section{Glutathione Level}

GSH levels were reduced by $36 \%$ in homTg lenses in comparison to Wt and hemTg lenses (Figure 8c). In 1-month-old homTg lenses, GSH levels were reduced by $\sim 13 \%$ in comparison to 1-month-old Wt lenses (Supplementary Figure S2). This suggests that the loss of GSH started to occur (along with KYN formation) before the onset of mature cataracts in homTg animals.

\section{Apoptosis}

TUNEL staining revealed apoptosis in the homTg lens nucleus (Figure 9a). Staining of the same sections for KYN modifications revealed that many cells that were TUNEL positive were also positive for KYN modifications (Figure 

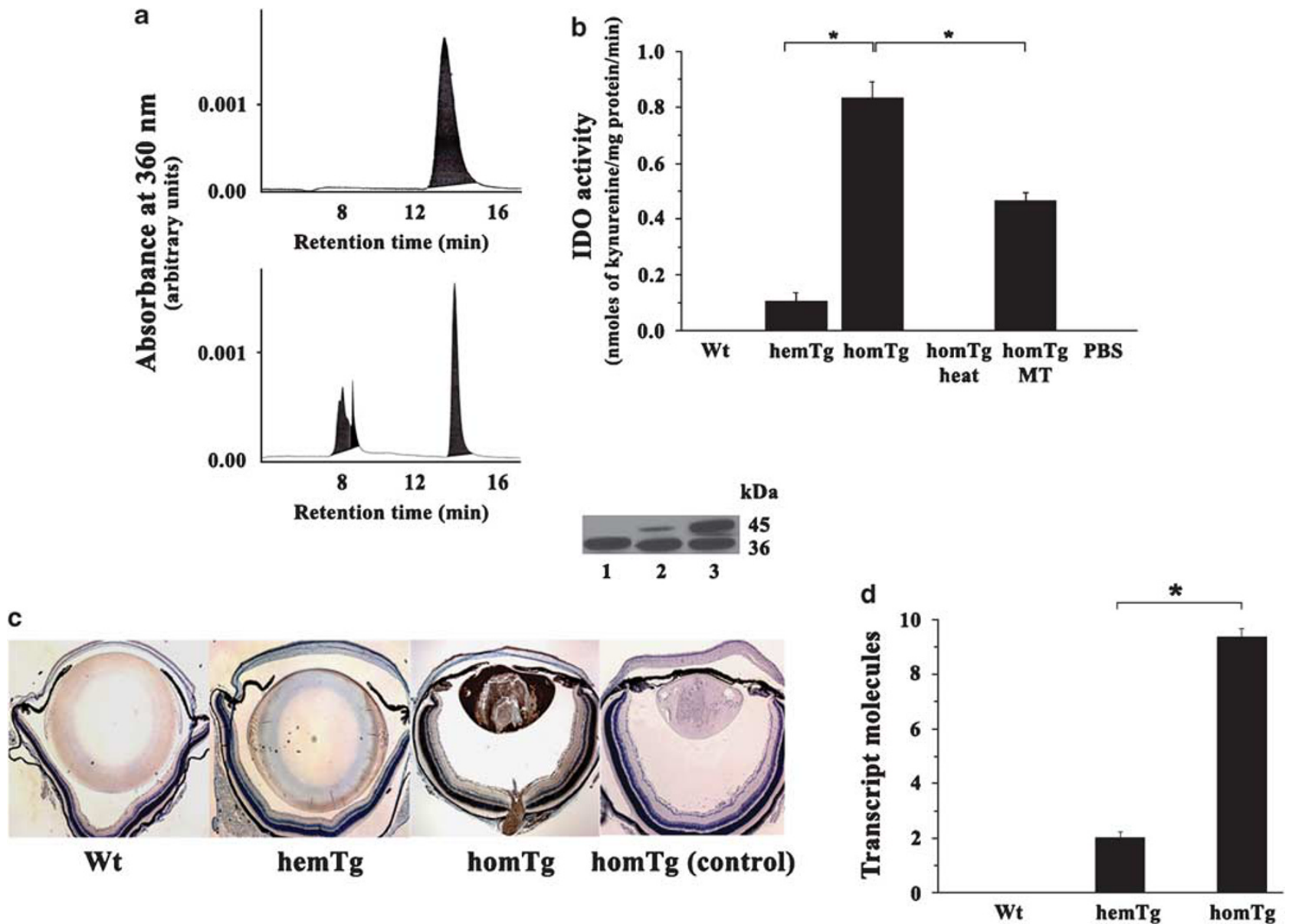

Figure 6 Indoleamine 2,3-dioxygenase (IDO) activity in the lens. IDO activity was estimated by measuring its product, kynurenine, by reverse-phase HPLC. (a) The elution profile of kynurenine showed that the peak between 12 and 14 min was kynurenine. Top panel, kynurenine standard and bottom panel, kynurenine in homTg lens extract. (b) homTg lenses had eightfold higher IDO activity than hemTg lenses. Methyltryptophan (MT)-treated homTg lens extract (homTg MT) had $40 \%$ less activity compared to the untreated sample, whereas the activity in Wt lens extract and heat-treated homTg lens extract (homTg heat) was negligible. Results shown are mean \pm s.d. of five lenses from five mice. ${ }^{\star} P<0.0001$. (c) Immunohistochemical localization of IDO in the lens. Prominent DAB staining (dark brown) was observed throughout the homTg lens. In hemTg lens, staining occurred only in the anterior epithelium and to some extent in the bow and outer posterior regions. Wt lens did not show appreciable DAB staining (magnification $\times 4$ ). The negative control (labeledcontrol), where the primary was omitted did not show DAB staining. The inset shows western blotting for IDO ( $45 \mathrm{kDa})$ in the water-soluble proteins using the IDO monoclonal antibody (1:5000 diluted). Lane 1, Wt; lane 2, hemTg; lane 3, homTg. GAPDH loading control (36 kDa) is also shown. (d) Quantitative real-time PCR analysis for hIDO mRNA showed that hIDO mRNA was 4.5-fold higher in homTg lens than in hemTg lens. In the Wt lens no hIDO mRNA was present. Results shown are mean \pm s.d. of five lenses from five mice. ${ }^{\star} P<0.0001$.

$9 b$ ), and that KYN modifications appeared to be present in both the cytoplasm and the nucleus. These findings suggest IDO overexpression causes apoptosis of fiber cells and could be due to KYN modifications of cytosolic and nuclear proteins and DNA. Apoptosis of fiber cells were seen, albeit to a lesser extent, in 1-month-old homTg lenses (Supplementary Figure S3). This, together with data in Supplementary Figures $\mathrm{S} 1 \mathrm{a}$ and $\mathrm{b}$, suggests that apoptosis, probably as a consequence of KYN formation, started to occur in precataractous lenses.

To further establish apoptosis in transgenic lenses, we measured caspase- 3 and caspase- 9 in lens homogenate. Caspase- 3 activity was fivefold higher in homTg lenses when compared to hemTg and Wt lenses (Figure 10a). Likewise, caspase-9 activity was fivefold higher in homTg animals compared to lenses from hemTg and Wt lenses (Figure 10b). These results suggest that IDO overexpression activates apoptosis in lens fiber cells.

\section{Identification of KYN-Modified Proteins}

Proteins from homTg lenses were immunoprecipitated using the KYN mAb. The immunoprecipitated proteins were separated on SDS-PAGE. Several protein bands were observed (Figure 11). The major protein band was subjected to mass spectrometry analysis. Several proteins, mostly $\beta$-crystallin subtypes, were identified, in addition to $\alpha \mathrm{A}$ - and $\alpha \mathrm{B}$-crystallins (Table 1). Our initial attempts to identify specific sites of KYN modification on $\beta$-crystallins were not successful, possibly because of structural diversity of modifications and/ 


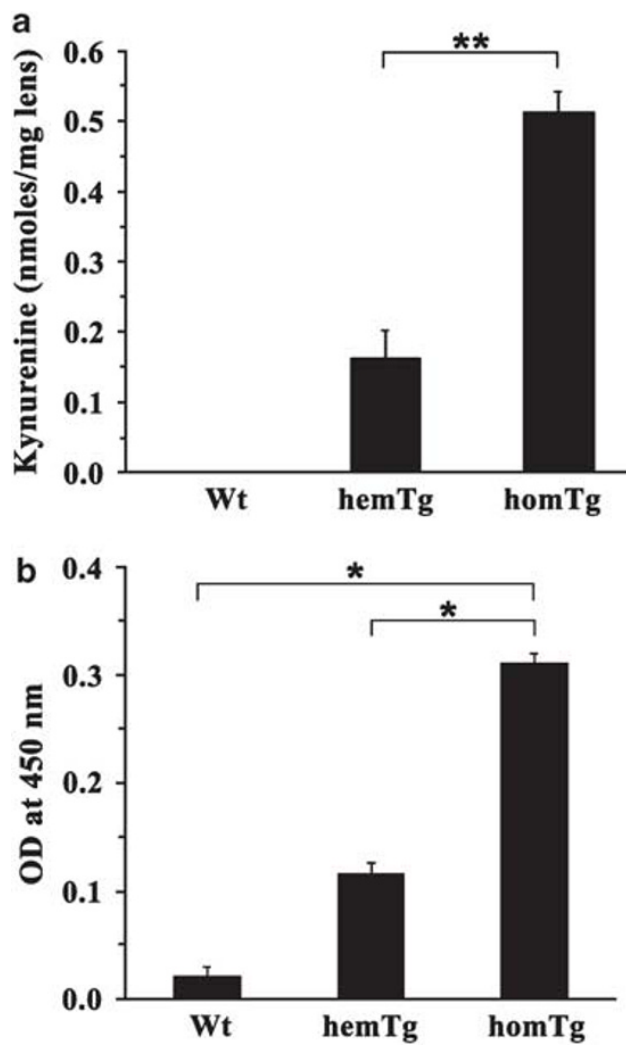

C
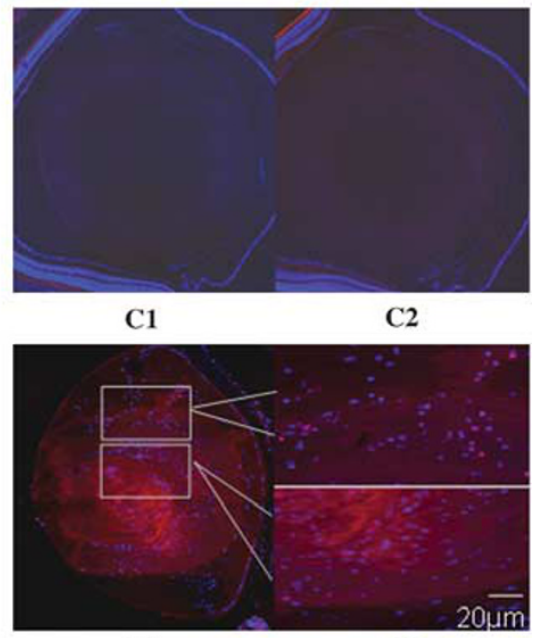

C3

C4

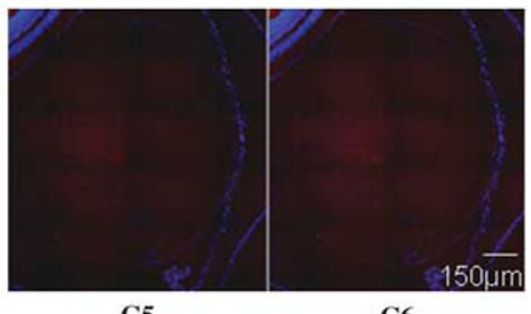

C5

C6

Figure 7 Lens kynurenine content and protein modification. (a) Kynurenine content was estimated by reverse-phase HPLC. Kynurenine content was threefold greater in homTg than in hemTg but was not detected in Wt lens. (b) ELISA for kynurenine-induced modifications of lens proteins. Modifications were $\sim 2.6$ times greater in homTg lens than in hemTg or Wt lens. Results shown are mean \pm s.d. of five independent experiments of five lenses from five mice. ${ }^{*} P<0.0001 ;{ }^{*} P=0.002$. (c) Immunostaining for kynurenine modification. Marked kynurenine modifications (red) were found in homTg lens (panel $C 3$ ) especially in the nucleus but not in Wt (panel C1) or hemTg (panel C2) lenses. Panel C4 presents regions at higher magnification to show kynurenine modification of nuclei (top) and fiber cells (bottom). The immune reactivity in homTg lens was markedly reduced in the absence of anti-kynurenine mAb (panel C5) and when the antibody was preincubated with kynurenine-modified RNase A (panel C6). Nuclei were stained with DAPI (blue) (magnification $\times 40$ ). Figures are representative of images obtained from three independent experiments.

or low abundance of modification relative to protein concentration, but we hope to identify such sites with more sophisticated approaches in the future. Our attempts to identify proteins by western blotting also failed. The KYN antibody did not react with proteins in western blotting (these proteins had relatively large quantities of KYN modification as judged by ELISA, see Figure 7b). We believe that the antigenic epitope gets masked or destroyed during SDSPAGE and/or western blotting (possibly by the reduction of the ketone group on the Michael adduct). Further studies are needed to verify this possibility.

\section{DISCUSSION}

The purpose of this study was to investigate the function of KYNs in lens protein modifications. We found that overexpression of IDO in the lens results in enhanced KYN formation. Thus, enough L-tryptophan must have been available to support the increased KYN formation. This is further supported by the finding that in organ-cultured homTg lenses, adding L-tryptophan enhanced KYN formation. We did not determine the amount of NFK formed, but because we detected higher levels of KYN in homTg animals as compared to hemTg or Wt animals, it suggests that kynurenine formamidase was not rate limiting. However, it is also possible that NFK was nonenzymatically converted to KYN. Second, the KYN produced from IDO reacted with proteins to form adducts that were detected by an $\mathrm{mAb}$ directed against KYN modification. We also found that KYN modification occurred in the cytosol and nuclei of fiber cells, and cells containing KYN modifications underwent apoptosis. Finally, IDO overexpression caused severe morphological changes in the lens. All our studies were carried out with 3-month-old lenses, the homTg lenses had dense cataracts at this time. The question arose as to whether cataract formation was related to KYN formation. Our data on lenses from 1-month-old homTg mice showed that the KYN content and KYN modification of proteins along with fiber cell apoptosis and GSH loss were already increased at this age. This suggests that further increase in these changes could have resulted in cataract formation in 3-month-old lenses (Figure 5). 

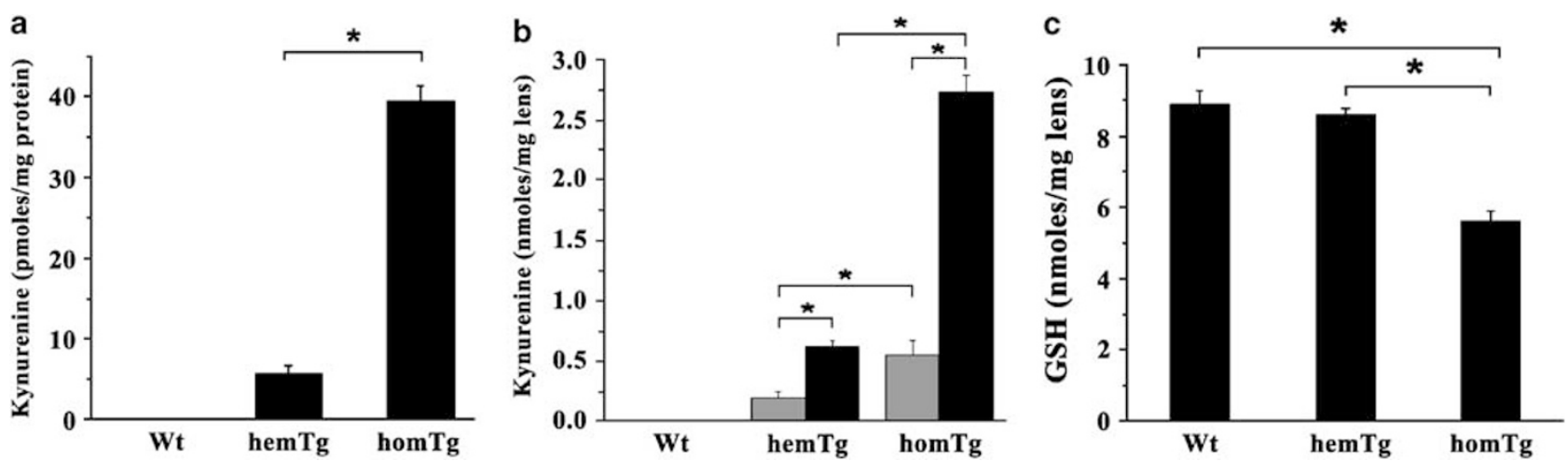

Figure 8 Kynurenine and GSH in the lens. (a) Incubation of lens proteins with L-tryptophan revealed an approximately sevenfold increase in kynurenine formation in homTg lenses relative to hemTg lenses. The Wt lens proteins did not produce kynurenine. (b) Lens organ culture with (black bar) and without (gray bar) L-tryptophan. Kynurenine content increased in transgenic lenses but not in Wt lens. (c) Lens GSH content decreased by $\sim 36 \%$ in homTg lenses relative to $\mathrm{Wt}$ and hemTg lenses. Results shown are mean \pm s.d. of five lenses from five mice. ${ }^{\star} P<0.0001$.

a \begin{tabular}{c} 
Wt \\
hemTg \\
homTg \\
\hline terminal \\
transferase
\end{tabular}
DAPI TUNEL DAPI+TUNEL
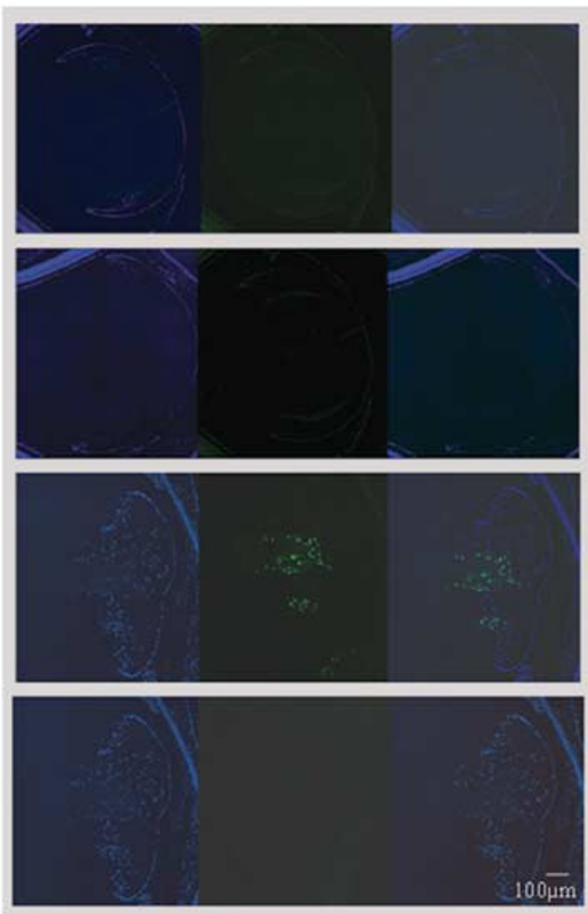

b DAPI+TUNEL

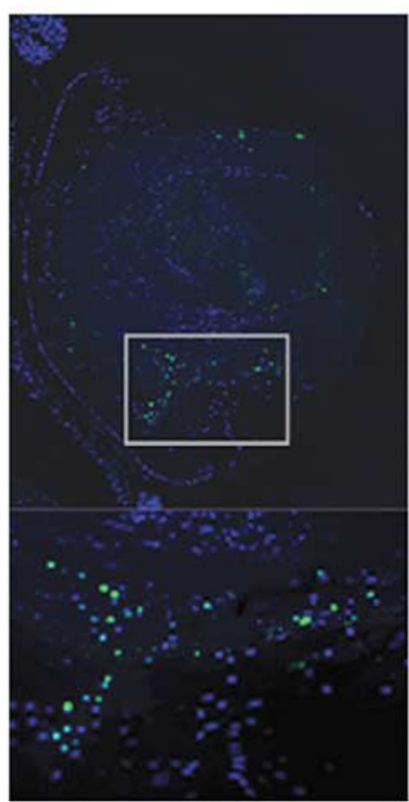

DAPI+Texas Red

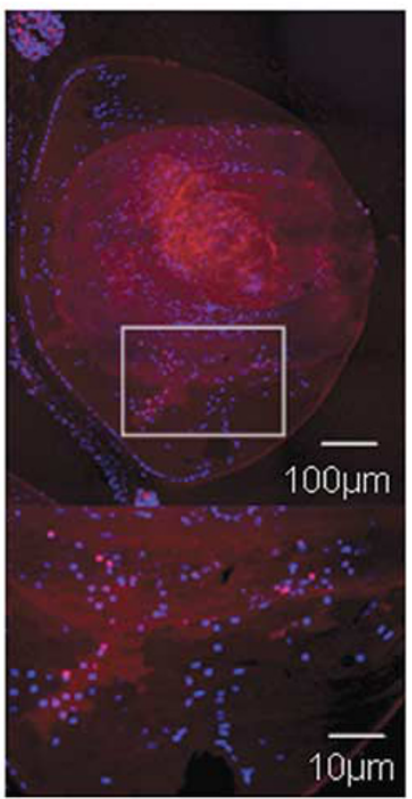

Figure 9 Apoptosis and kynurenine modification in the lens. (a) TUNEL-positive cells (green) were detected in homTg lens but not in Wt and hemTg lenses or in homTg lens incubated without terminal transferase. Nuclei were stained with DAPI (blue) (magnification $\times 40$ ). (b) Cells that were positive for TUNEL (green) were also positive for kynurenine modifications (red) (magnification $\times 40$ ). Images in the lower panels are sections magnified from the panels above. Figures are representative of images obtained from three independent experiments.

KYNs must be deaminated to produce adducts in proteins. GSH is believed to inhibit such adduction by binding to KYN. Mammalian lenses, including those in human, have high levels of GSH. ${ }^{32}$ However, in aging and cataractous lenses, GSH levels are reduced, ${ }^{33,34}$ which could lead to increased KYN modification of proteins. Our data showing that GSH levels are significantly reduced in homTg lenses further support this view. It is also possible that reactive oxygen species produced from $\mathrm{KYNs}^{35}$ could have oxidized GSH and promoted reaction between KYN and proteins. It is noteworthy that in ground-squirrel lenses, even though KYN levels are relatively high, the lenses are clear, possibly because the GSH level is also extremely high. ${ }^{36}$ 
It is possible that the severe morphological changes observed with IDO overexpression were due to overexpression of the protein alone rather than its associated increased activity. However, our finding that the glyoxalase-I-overexpression mice, which have the same transgene construct
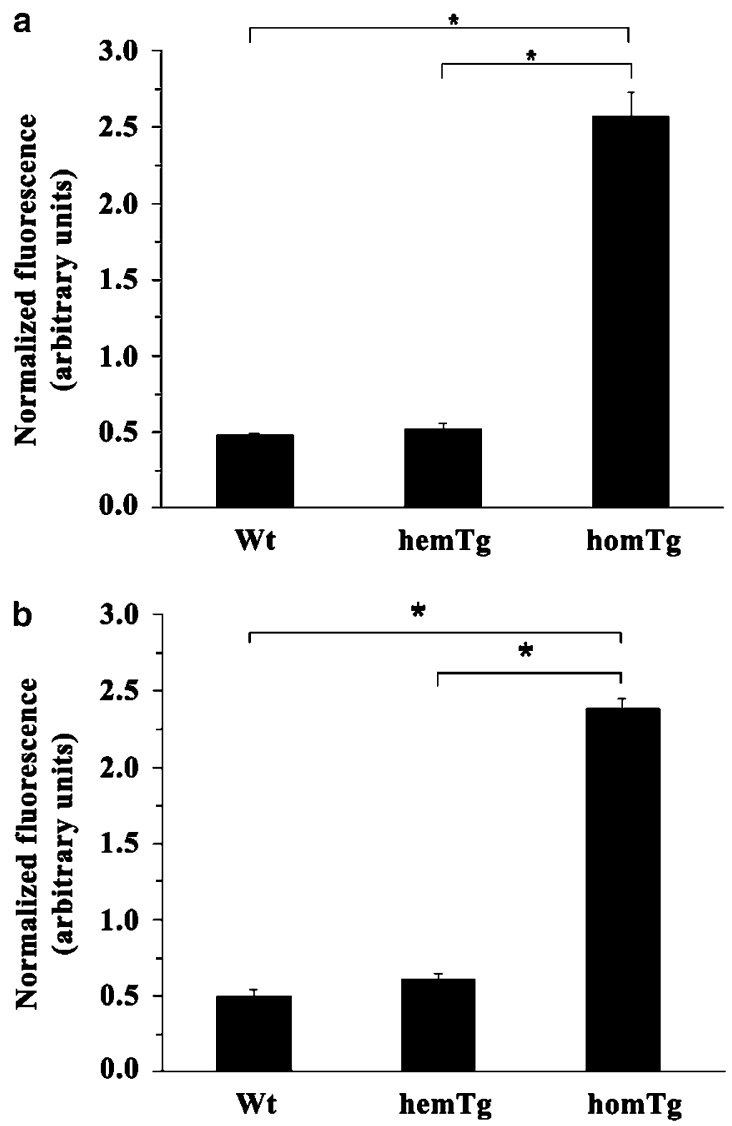

Figure 10 Caspase activity in the lens. (a) Caspase-3 activity in the homTg lens was significantly higher than in Wt and hemTg lenses. (b) Caspase-9 activity was significantly higher in homTg lens compared with Wt and hemTg lenses. Results shown are mean \pm s.d. of five independent experiments of five lenses from five mice. ${ }^{\star} P<0.0001$. but normal morphology, rules out such an effect. Therefore, it is likely that enhanced IDO expression and activity led to the morphological defects seen in the IDO transgenic lenses.

The morphological changes were highlighted by improper terminal differentiation of fiber cells (ie, nucleated). During normal lens development, epithelial cells stop dividing at the lens equatorial region and differentiate into elongated fiber cells, during which time they lose their nuclei and other organelles. ${ }^{37}$ The poor differentiation we observed suggests a serious abnormality in organelle degradation. Although the precise mechanisms for organelle degradation are not known,

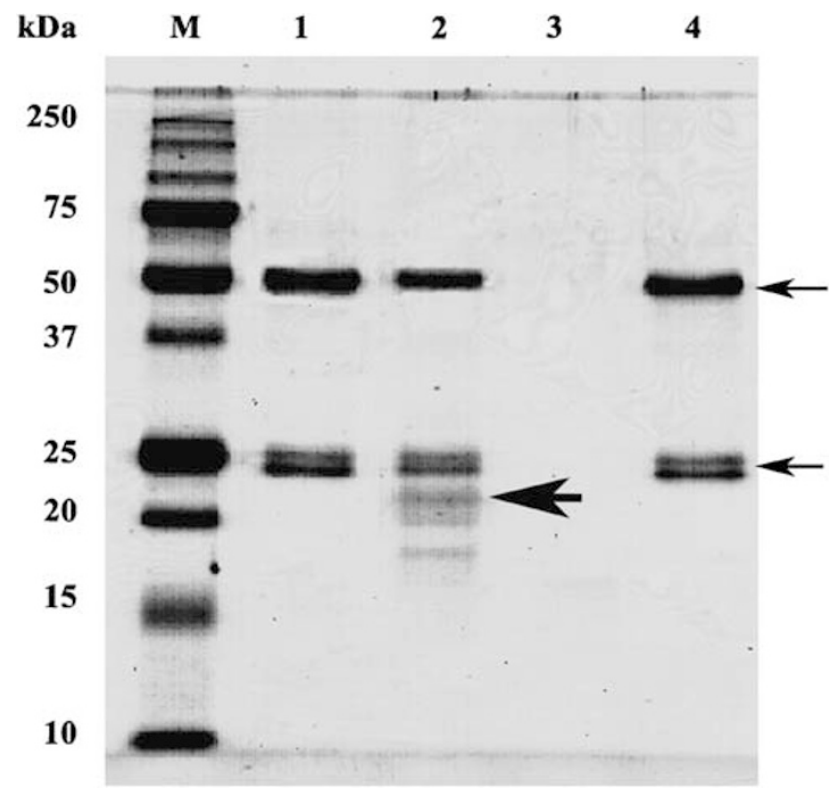

Figure 11 Identification of KYN-modified proteins. Water-soluble lens proteins were incubated with KYN antibody, Protein A/G sepharose gel was pelleted and subjected to SDS-PAGE followed by western blotting using KYN antibody. The major protein band (thick arrow) was analyzed by mass spectrometry and the results are presented in Table 1. Lane 1, Wt lens extract; lane 2, homTg lens extract; lane 3, Gel + homTg lens extract; lane 4, $\mathrm{Gel}+\mathrm{Ab}$. The heavy and light chains of the antibody are indicated by thin arrows.

Table 1 KYN mAb binding proteins identified by LC/MS

\begin{tabular}{|c|c|c|c|c|c|}
\hline Protein ID & Protein name & Mass & Sequence coverage (\%) & Mascot score & Unique peptide \\
\hline CRBA1_MOUSE (P02525) & $\beta$-Crystallin A1 & 23387 & 78 & 2047 & 11 \\
\hline CRBA4_MOUSE (Q9JJV0) & $\beta$-Crystallin A4 & 22324 & 66 & 1409 & 8 \\
\hline CRBA2_MOUSE (Q9JJV1) & $\beta$-Crystallin A2 & 22092 & 54 & 1262 & 7 \\
\hline CRYAB_MOUSE (P23927) & $\alpha$-Crystallin B chain & 20056 & 68 & 802 & 9 \\
\hline CRBB1_MOUSE (Q9WVJ5) & $\beta$-Crystallin B1 & 27854 & 41 & 572 & 8 \\
\hline CRBB2_MOUSE (P62696) & $\beta$-Crystallin B2 & 23235 & 44 & 359 & 8 \\
\hline
\end{tabular}


it is believed that a gradient formed by diffusible substances, in particular intracellular oxygen, is one cause. ${ }^{38}$ It is possible that in the homTg lenses, such a gradient was altered and resulted in the loss of cues necessary for organelle degradation.

The absence of differentiation may also be due to an effect of KYNs on cell signaling, transcription, and growth factors. Fibroblast growth factor, IGF-1, and bone morphogenetic protein have been implicated in stimulation of fiber cell differentiation. ${ }^{39-42}$ In addition, it has been demonstrated that the PI3K pathway regulates initiation of lens cell differentiation by signaling a reorganization of the actin cytoskeleton from stress fibers to cortical fibers. ${ }^{43}$ Furthermore, targeted mutations in the genes encoding c-Maf, Soxl, and Proxl have all resulted in specific defects in fiber cell differentiation, ${ }^{44-46}$ implicating these transcription factors in epithelial cell differentiation. KYNs may have affected any one of these factors, thereby affecting fiber cell differentiation. Such effects of KYN may be due to chemical modifications of proteins or through formation of reactive oxygen species. The mass spectrometric analysis of proteins from homTg lenses suggested that major proteins of the lens $(\alpha$ - and $\beta$-crystallins) are modified by KYN. For that analysis, we selected only the major band from the SDS-PAGE of the immunoprecipitated sample (Figure 11). Other minor protein bands that were not analyzed might contain proteins that are involved in fiber cell differentiation. Further work is needed to verify this possibility.

Several previous studies have shown that extracellular KYNs can induce apoptosis, ${ }^{47-49}$ but none has demonstrated that intracellular KYN formation can induce apoptosis. Our study strongly implicates intracellular KYNs, KYN modifications, or both in apoptosis. Although we did not determine whether nuclear protein or DNA modification was required, such an event is likely. The idea that KYNs induce fiber cell apoptosis is supported by a recent study showing that kidney tubular epithelial cells that overexpress IDO undergo apoptosis, ${ }^{15}$ possibly through formation of KYNs. Another recent study showed that fiber cells undergo apoptosis in $\alpha \mathrm{A} / \alpha \mathrm{B}$-crystallin knockout mice, suggesting a function for $\alpha$-crystallins in preventing fiber cell apoptosis. ${ }^{50}$ Whether $\alpha$-crystallin's potential ability to inhibit apoptosis was compromised in homTg animal lenses is uncertain, but KYN modification can cause the loss of chaperone function, ${ }^{30,51}$ which is likely related to $\alpha$-crystallin's anti-apoptotic activity. It is probable that KYNs affected FGF-R signaling, as it is required for early and late fiber cell differentiation and survival of terminally differentiated fiber cells. ${ }^{52}$

Only the homTg mice exhibited reduced eye size, which is common in transgenic mouse models that lack growth factors or proteins involved in cell-cycle regulation. ${ }^{53,54} \mathrm{In}$ activation of Rho GTPase by selective expression of the C3exoenzyme $\mathrm{e}^{55}$ or expression of diphtheria toxin with regulatory sequences associated with $\gamma 2$-crystallin gene ${ }^{56}$ also results in a smaller lens and microphthalmia in mice. It is possible that diphtheria toxin and KYNs exert similar cytotoxic effects that lead to lens developmental defects and smaller lenses.

In the lens, IDO is present primarily in epithelial cells. In the normal transparent lens, IDO activity may be kept to a minimum so that its activity is sufficient to produce the low quantity of KYN needed to filter out UV light. Such regulation of IDO activity might occur at posttranslational level. IDO activity has been reported to be inhibited by NO and $\mathrm{H}_{2} \mathrm{O}_{2}{ }^{57,58}$ Both modifications are reversible and therefore could be involved in regulating IDO activity. During anterior segment infection, interferon- $\gamma$ increases in the aqueous humor. If IDO activity goes unchecked due to stimulation by interferon- $\gamma$, then the enhanced IDO activity in the lens may impart considerable damage. In fact, elevated levels of aqueous humor interferon- $\gamma$ concentrations are associated with cataract formation, ${ }^{59}$ and ectopic expression of interferon- $\gamma$ disrupts fiber cell differentiation and leads to cataract formation in mice. ${ }^{60,61}$ It will be of interest to determine whether IDO activity is elevated and consequently $\mathrm{KYN}$ production enhanced when interferon- $\gamma$ is elevated in the lens.

In summary, our study provides the first evidence that KYNs formed within the lens are cytotoxic and bring about changes that are similar to those that occur during cataract formation. This animal model may also be useful for understanding pathologies of other diseases, such as Alzheimer's and Parkinson's diseases, where KYNs appear to be involved.

Supplementary Information accompanies the paper on the Laboratory Investigation website (http://www.laboratoryinvestigation.org)

\section{ACKNOWLEDGEMENT}

This study was supported from NIH grants R01EY-016219 and R01EY-09912 (RHN), P30EY-11373 (the Visual Sciences Research Center of CWRU); the Carl F Asseff, MD Professorship (RHN); Research to Prevent Blindness, NY; and the Ohio Lions Eye Research Foundation. We thank Mark Harrod for help with slit lamp imaging of lenses.

1. King NJ, Thomas SR. Molecules in focus: indoleamine 2,3-dioxygenase. Int J Biochem Cell Biol 2007;39:2167-2172.

2. Takikawa O. Biochemical and medical aspects of the indoleamine 2,3-dioxygenase-initiated L-tryptophan metabolism. Biochem Biophys Res Commun 2005;338:12-19.

3. MacKenzie $C R$, Heseler $K$, Muller $A$, et al. Role of indoleamine 2,3-dioxygenase in antimicrobial defence and immuno-regulation: tryptophan depletion versus production of toxic kynurenines. Curr Drug Metab 2007:8:237-244.

4. Fallarino F, Gizzi S, Mosci P, et al. Tryptophan catabolism in IDO+ plasmacytoid dendritic cells. Curr Drug Metab 2007;8:209-216.

5. Mellor AL, Munn D, Chandler P, et al. Tryptophan catabolism and T cell responses. Adv Exp Med Biol 2003;527:27-35.

6. Li Y, Tredget EE, Ghaffari A, et al. Local expression of indoleamine 2,3-dioxygenase protects engraftment of xenogeneic skin substitute. J Invest Dermatol 2006;126:128-136.

7. Brandacher G, Cakar F, Winkler C, et al. Non-invasive monitoring of kidney allograft rejection through IDO metabolism evaluation. Kidney Int 2007;71:60-67. 
8. Zamanakou M, Germenis AE, Karanikas V. Tumor immune escape mediated by indoleamine 2,3-dioxygenase. Immunol Lett 2007;111:69-75.

9. Muller AJ, DuHadaway JB, Donover PS, et al. Inhibition of indoleamine 2,3-dioxygenase, an immunoregulatory target of the cancer suppression gene Bin1, potentiates cancer chemotherapy. Nat Med 2005;11:312-319.

10. Okuda S, Nishiyama N, Saito $\mathrm{H}$, et al. 3-Hydroxykynurenine, an endogenous oxidative stress generator, causes neuronal cell death with apoptotic features and region selectivity. J Neurochem 1998;70:299-307.

11. Morita T, Saito K, Takemura M, et al. 3-Hydroxyanthranilic acid, an L-tryptophan metabolite, induces apoptosis in monocyte-derived cells stimulated by interferon-gamma. Ann Clin Biochem 2001;38:242-251.

12. Wirleitner B, Rudzite $V$, Neurauter $G$, et al. Immune activation and degradation of tryptophan in coronary heart disease. Eur J Clin Invest 2003;33:550-554.

13. Tankiewicz A, Pawlak D, Topczewska-Bruns J, et al. Kidney and liver kynurenine pathway enzymes in chronic renal failure. Adv Exp Med Biol 2003;527:409-414.

14. Sala A, Campagnoli M, Perani E, et al. Human alpha-1-microglobulin is covalently bound to kynurenine-derived chromophores. J Biol Chem 2004;279:51033-51041.

15. Mohib K, Guan Q, Diao H, et al. Proapoptotic activity of indoleamine 2,3-dioxygenase expressed in renal tubular epithelial cells. Am J Physiol Renal Physiol 2007;293:F801-F812.

16. Cerstiaens A, Huybrechts J, Kotanen S, et al. Neurotoxic and neurobehavioral effects of kynurenines in adult insects. Biochem Biophys Res Commun 2003;312:1171-1177.

17. Pearson SJ, Meldrum A, Reynolds GP. An investigation of the activities of 3-hydroxykynureninase and kynurenine aminotransferase in the brain in Huntington's disease. J Neural Transm Gen Sect 1995;102:67-73.

18. Ogawa T, Matson WR, Beal MF, et al. Kynurenine pathway abnormalities in Parkinson's disease. Neurology 1992;42:1702-1706.

19. Sas K, Robotka H, Toldi J, et al. Mitochondria, metabolic disturbances, oxidative stress and the kynurenine system, with focus on neurodegenerative disorders. J Neurol Sci 2007;257:221-239.

20. Schrocksnadel K, Wirleitner B, Winkler C, et al. Monitoring tryptophan metabolism in chronic immune activation. Clin Chim Acta 2006;364:82-90.

21. Szanto S, Koreny T, Mikecz K, et al. Inhibition of indoleamine 2,3dioxygenase-mediated tryptophan catabolism accelerates collageninduced arthritis in mice. Arthritis Res Ther 2007;9:R50.

22. Takikawa O, Littlejohn T, Jamie JF, et al. Regulation of indoleamine 2,3dioxygenase, the first enzyme in UV filter biosynthesis in the human lens. Relevance for senile nuclear cataract. Adv Exp Med Biol 1999;467:241-245.

23. Bova LM, Sweeney MH, Jamie JF, et al. Major changes in human ocular UV protection with age. Invest Ophthalmol Vis Sci 2001;42: 200-205.

24. Taylor LM, Andrew Aquilina J, Jamie JF, et al. UV filter instability: consequences for the human lens. Exp Eye Res 2002;75:165-175.

25. Vazquez S, Aquilina JA, Jamie JF, et al. Novel protein modification by kynurenine in human lenses. J Biol Chem 2002;277: 4867-4873.

26. Korlimbinis A, Aquilina JA, Truscott RJ. Protein-bound UV filters in normal human lenses: the concentration of bound UV filters equals that of free UV filters in the center of older lenses. Invest Ophthalmol Vis Sci 2007;48:1718-1723.

27. Vazquez S, Parker NR, Sheil M, et al. Protein-bound kynurenine decreases with the progression of age-related nuclear cataract. Invest Ophthalmol Vis Sci 2004;45:879-883.

28. Staniszewska MM, Nagaraj RH. 3-Hydroxykynurenine-mediated modification of human lens proteins: structure determination of a major modification using a monoclonal antibody. J Biol Chem 2005;280:22154-22164.

29. Staniszewska M, Nagaraj RH. Detection of kynurenine modifications in proteins using a monoclonal antibody. J Immunol Methods 2007;324:63-73

30. Bhattacharyya J, Padmanabha Udupa EG, Wang J, et al. Mini-alphaBcrystallin: a functional element of alphaB-crystallin with chaperone-like activity. Biochemistry 2006;45:3069-3076.
31. Cui XL, Lou MF. The effect and recovery of long-term $\mathrm{H} 2 \mathrm{O} 2$ exposure on lens morphology and biochemistry. Exp Eye Res 1993;57: 157-167.

32. Giblin FJ. Glutathione: a vital lens antioxidant. J Ocul Pharmacol Ther 2000;16:121-135.

33. Kamei A. Glutathione levels of the human crystalline lens in aging and its antioxidant effect against the oxidation of lens proteins. Biol Pharm Bull 1993;16:870-875.

34. Reddy VN, Giblin FJ. Metabolism and function of glutathione in the lens. Ciba Found Symp 1984;106:65-87.

35. Hwu P, Du MX, Lapointe R, et al. Indoleamine 2,3-dioxygenase production by human dendritic cells results in the inhibition of $\mathrm{T}$ cell proliferation. J Immunol 2000;164:3596-3599.

36. Hains PG, Simpanya MF, Giblin F, et al. UV filters in the lens of the thirteen lined ground squirrel (Spermophilus tridecemlineatus). Exp Eye Res 2006;82:730-737.

37. Piatigorsky J. Lens differentiation in vertebrates. A review of cellular and molecular features. Differentiation 1981;19: 134-153.

38. Bassnett $S$, McNulty R. The effect of elevated intraocular oxygen on organelle degradation in the embryonic chicken lens. J Exp Biol 2003;206:4353-4361.

39. Beebe DC, Silver MH, Belcher KS, et al. Lentropin, a protein that controls lens fiber formation, is related functionally and immunologically to the insulin-like growth factors. Proc Natl Acad Sci USA 1987;84:2327-2330.

40. Lovicu FJ, McAvoy JW. Growth factor regulation of lens development. Dev Biol 2005;280:1-14

41. Belecky-Adams TL, Adler R, Beebe DC. Bone morphogenetic protein signaling and the initiation of lens fiber cell differentiation. Development 2002;129:3795-3802.

42. Peek R, McAvoy JW, Lubsen $\mathrm{NH}$, et al. Rise and fall of crystallin gene messenger levels during fibroblast growth factor induced terminal differentiation of lens cells. Dev Biol 1992;152:152-160.

43. Weber GF, Menko AS. Phosphatidylinositol 3-kinase is necessary for lens fiber cell differentiation and survival. Invest Ophthalmol Vis Sci 2006;47:4490-4499.

44. Ring BZ, Cordes SP, Overbeek PA, et al. Regulation of mouse lens fiber cell development and differentiation by the Maf gene. Development 2000;127:307-317.

45. Nishiguchi $\mathrm{S}$, Wood $\mathrm{H}$, Kondoh $\mathrm{H}$, et al. Sox 1 directly regulates the gamma-crystallin genes and is essential for lens development in mice. Genes Dev 1998;12:776-781.

46. Wigle JT, Chowdhury K, Gruss $\mathrm{P}$, et al. Prox 1 function is crucial for mouse lens-fibre elongation. Nat Genet 1999;21:318-322.

47. Fallarino F, Grohmann U, Vacca C, et al. T cell apoptosis by kynurenines. Adv Exp Med Biol 2003;527:183-190.

48. Morita T, Saito K, Takemura M, et al. L-tryptophan-kynurenine pathway metabolite 3-hydroxyanthranilic acid induces apoptosis in macrophage-derived cells under pathophysiological conditions. Adv Exp Med Biol 1999;467:559-563.

49. Wei $H$, Leeds $P$, Chen RW, et al. Neuronal apoptosis induced by pharmacological concentrations of 3-hydroxykynurenine: characterization and protection by dantrolene and $\mathrm{Bcl}-2$ overexpression. J Neurochem 2000;75:81-90.

50. Morozov V, Wawrousek EF. Caspase-dependent secondary lens fiber cell disintegration in alphaA-/alphaB-crystallin double-knockout mice. Development 2006;133:813-821.

51. Aquilina JA, Truscott RJ. Kynurenine binds to the peptide binding region of the chaperone alphaB-crystallin. Biochem Biophys Res Commun 2001;285:1107-1113.

52. Stolen CM, Griep AE. Disruption of lens fiber cell differentiation and survival at multiple stages by region-specific expression of truncated FGF receptors. Dev Biol 2000;217:205-220.

53. Fromm L, Shawlot W, Gunning $K$, et al. The retinoblastoma proteinbinding region of simian virus 40 large $T$ antigen alters cell cycle regulation in lenses of transgenic mice. Mol Cell Biol 1994;14: 6743-6754.

54. Lovicu FJ, Overbeek PA. Overlapping effects of different members of the FGF family on lens fiber differentiation in transgenic mice. Development 1998;125:3365-3377

55. Rao V, Wawrousek E, Tamm ER, et al. Rho GTPase inactivation impairs lens growth and integrity. Lab Invest 2002;82:231-239. 
56. Breitman $\mathrm{ML}$, Rombola $\mathrm{H}$, Maxwell $\mathrm{IH}$, et al. Genetic ablation in transgenic mice with an attenuated diphtheria toxin A gene. Mol Cell Biol 1990;10:474-479.

57. Thomas SR, Mohr D, Stocker R. Nitric oxide inhibits indoleamine 2,3-dioxygenase activity in interferon-gamma primed mononuclear phagocytes. J Biol Chem 1994;269:14457-14464.

58. Poljak A, Grant R, Austin CJ, et al. Inhibition of indoleamine 2,3 dioxygenase activity by $\mathrm{H} 2 \mathrm{O} 2$. Arch Biochem Biophys 2006;450: 9-19.
59. Lacomba MS, Martin CM, Chamond RR, et al. Aqueous and serum interferon gamma, interleukin (IL) 2, IL-4, and IL-10 in patients with uveitis. Arch Ophthalmol 2000;118:768-772.

60. Awasthi N, Wagner BJ. Interferon-gamma induces apoptosis of lens alphaTN4-1 cells and proteasome inhibition has an antiapoptotic effect. Invest Ophthalmol Vis Sci 2004;45:222-229.

61. Geiger K, Howes E, Gallina M, et al. Transgenic mice expressing IFNgamma in the retina develop inflammation of the eye and photoreceptor loss. Invest Ophthalmol Vis Sci 1994;35:2667-2681. 